DEEP-SEA DREDGING AND LIFE IN THE $D E E P S E A^{=}$

II.

THE surface-water of the ocean is inhabited by an abundant animal fauna peculiar to itself, and termed pelagic. In ubiquity of geographical distribution the animal forms composing this fauna approach very nearly the fauna of the deep-sea bottom. There appears to be a marked relation between the pelagic fauna and the deep-sea fauna. Almost all the deep-sea forms have closely-allied

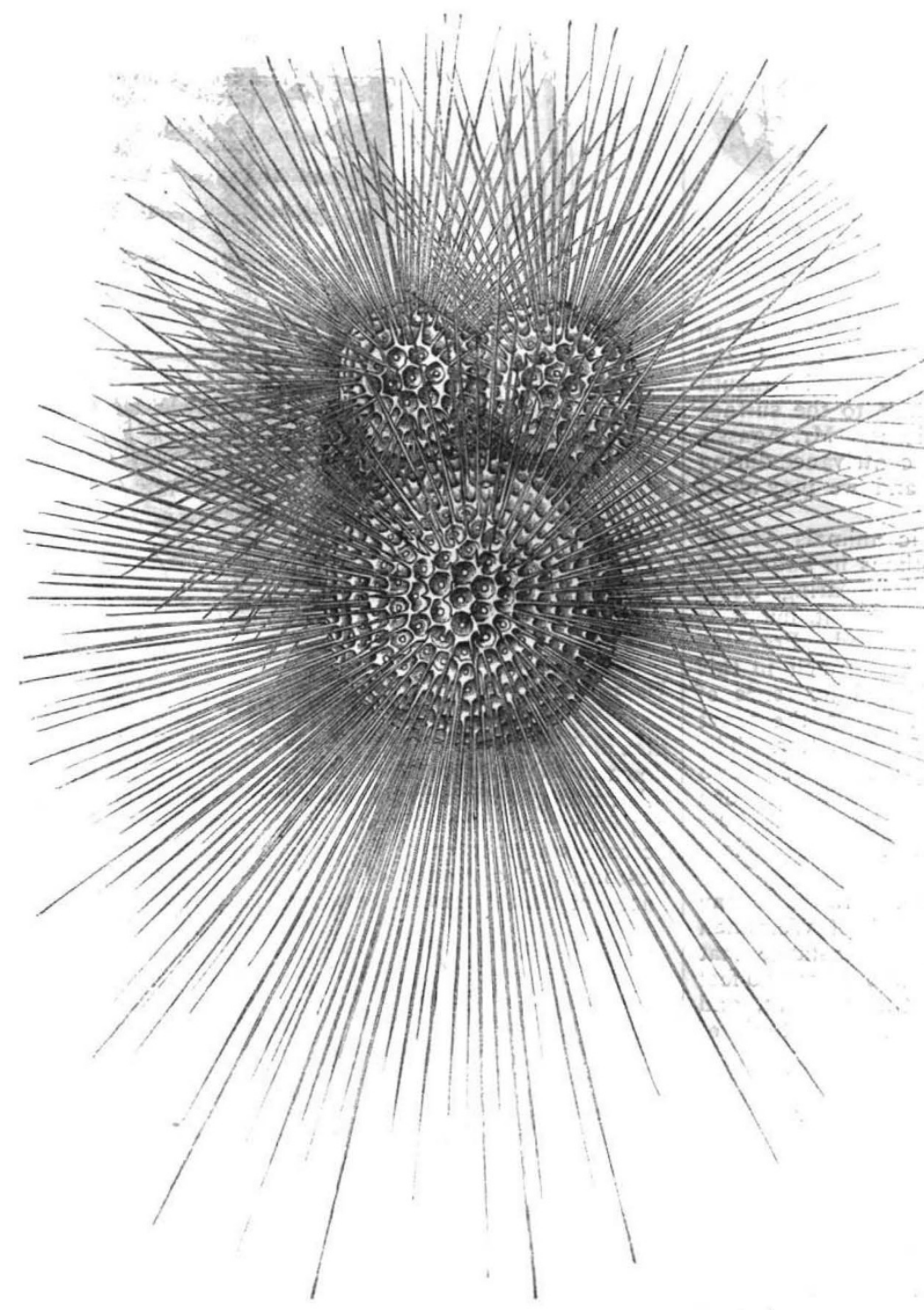

FIG. 10.-Pelagic Globigerina. Much magnified.

Here is one of these surface Rhizopods, a Globigerina which, like most, but not all, of the Globigerinæ occurring at the surface, is covered with delicate calcareous spines projecting from its shell. That the deep-sea bottom is over vast areas covered by a mud composed mainly of Globigerina shells like this one, but without the spines, is well known to all my hearers.

An important question which has been much disputed is, whether the Globigerina mud is entirely derived from the surface, being made up of dead shells fallen from above, or whether the shells composing it live on the bottom. Mr. Henry Brady, after examining all the Challenger collections, concludes that the main components of the mud do live on the bottom. Certain species found there do not occur on the surface at all, and Globigerinæ occur on the bottom near our own shores, where none have ever been found on the surface. Further, the shells of the specimens found on the deep-sea bottom are much larger and thicker than any yet found on the surface. Here are some deep-sea Rhizopoda, concerning which there has never been any doubt as to their living on the deep-sea bottom. Dr. Carpenter described many such long ago. The accompanying illustrations (Fig. $\mathrm{II}, a, b, c$ ) are from Mr. Brady's figures. These Rhizopods are called arenaceous, because their shells are mostly made up of sand particles and foreign bodies of all kinds glued together. These arenaceous Rhizopods are abundant all over the world, and reach down to the greatest depths. One, shown in the figure $(a)$, from 2,760 fathoms, has included sponge spicules in its test. Another one (b) is from 2,900 fathoms. It is chambered somewhat like a Globigerina. This other one $(c)$ is attached to a heavy body, a sufficient evidence, were any required, that they lived on the bottom.

Supposing that Globigerinæ do live at the bottom as well as at the surface, do they also live at intermediate depths? This opens the most important question which at present remains to be solved with regard to deep-sea life. It applies not only to Globigerinæ, but to all the vast pelagic fauna to which I have referred. Do the jelly-fish, the crustacea, the mollusca, and other animals so abundant in surface waters inhabit also the depths of the mid-ocean, or is there a vast azoic area between the surface and the bottom untenanted by life in any form? To this question we can at representatives floating or swimming near the ocean surface. The deep-sea sea-anemonies are represented on the surface by floating sea-anemonies. There are surfaceworms, hydroids, bryozoa, barnacles, and fish represented by close allies on the deep-sea bottom. Lastly, there are abundance of surface Rhizopoda corresponding with the vast quantities of them below (Fig. I0).

Friday Evening Lecture delivered at the Royal Institution on March 5, by H. N. Moseley, F.R.S., Assistant Registrar of the University of London. Continued from p. 547 . present return no answer of any value. The trawls used by the Challenger swept, in going down to the bottom and coming up again, the whole stretch of the sea from top to bottom, and it is impossible to tell whether pelagic animals found in it when it reached the surface were caught there or at the bottom. Mr. Murray used the towing-net at various depths, but the same objection applies to the results. Deep-sea Medusæ have been described by Prof. Haeckel and deep-see Siphonophora by Prof. Studer, but both may have come from very small depths. 
What is wanted to determine the problem is a net which can be let down to any required depth, securely closed, then be opened and towed for some time, then closed again and brought to the surface. Its contents would then be certainly derived from the depth at which it was towed. I devised, some months ago, a net which will, I believe, answer these requirements. Its mouth, which is fastened on a hinged frame, is kept shut by means of springs, but can be opened by the action of a pair of electromagnets excited by a battery on board
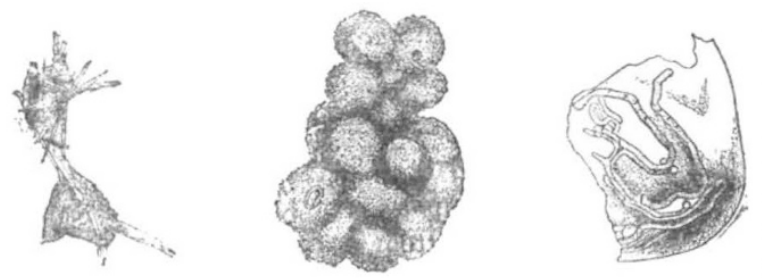

FIG. Ir.-Arenaceous Rhizopoda. a, Astrorhiza catenaía, 2,760 fathoms; $b$, Sorosphara confusa, 900 to 2,900 fathoms: c, Hyperammina vagans attached to a piece of shell, 2, $\infty 0$ fathoms. (After H. B. Brady; F.R.S., Quart. Fourn, Micro. Sci., vol. xix., new series).

ship. A rope is used to tow the net, which contains an insulated wire. Whilst the net is being towed, the magnets are maintained in action and keep its mouth open. As soon as the net is to be drawn to the surface the current is stopped, and the net closes. Mr. Agassiz intends to use this net or some better contrivance during this summer on the American coast, and we may await the results with great interest. ${ }^{1}$

It has long been known that pelagic animals change their level constantly, appearing sometimes in swarms at the very surface of the sea, and again disappearing. Some come up in calm weather, others only at night, but it is quite uncertain to what depths they descend. Probably the different pelagic animals vary very much in this respect, and they may each have their definite zones of range. It would be most interesting to learn the exact habits of such animals as Pteropods in this matter. The question could easily be determined by the use of such a net as I have described for a short period at any one locality, and most valuable results might be obtained by any one who cared to take the matter up in the neighbourhood of our own coasts.

Very possibly the pelagic animals do not range to any great depth, 100 or 150 fathoms, or less. Prof. Weissman concludes from his researches at Lake Constance that the surface animals there sink to a depth of about 50 feet in the day-time in order to escape the sunlight, and rise slowly in the evening, following the rising limit of darkness in the water.

It is quite possible that a vast stretch of water between the surface and the bottom is nearly or absolutely without life.

There are a large number of animals, some of the most curious forms, which most probably do not live at the bottom of the sea, but which constantly appeared in our trawl-net when used in great depths. Amongst these are a large number of fish of great rarity. They may have come from 20 fathoms or from 2,000. We cannot tell. Possibly they live at 60 or 100 fathoms, and rarely reach the surface; hence their scarcity. Some certainly pelagic animals, which are very scarce, probably live at a considerable depth from the surface.

Here (Fig. 12) is a very scarce animal indeed, a pelagic Nemertine worm. The Nemertines mostly live on the seabottom, and are long and worm-like. This is one which has become so modified to live a pelagic existence as to resemble them in appearance very little. Its body has

${ }^{x}$ Since this lecture was sent to the printers I have heard from Mr. Agassiz that Capt. Sigsbee has invented a net which he expects will do all that is wanted with complete efficiency. become transparent like glass, that the animal may become almost invisible to its enemies, whilst the branching intestine, the only part which could not be rendered translucent, has become brown-coloured, as in several other pelagic animals, to imitate floating sea-weed. The proboscis projected from the head shows the animal at once to be a Nemertine. I have called it Pelagonemertes. One speci-
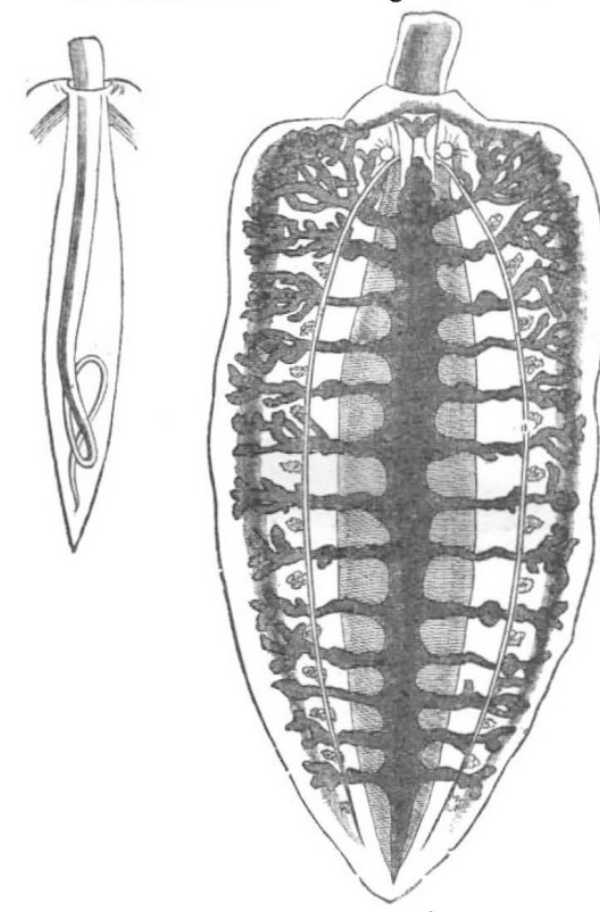

FIG. $x 2 . x-$ Pelagonenertes Rollestoni. On the left the proboscis sheath with the proboscis coiled up inside.

men of this animal was found in the trawlafter it had been down to I, 800 fathoms, to the south of Australia. Another was got off Japan when the net had been down to 755 fathoms. The animal was only found on these two occasions at these widely distant spots. Fifty years ago Lesson, on the voyage of the Coquille, found in abundance, on the sea-surface between the Moluccas and New

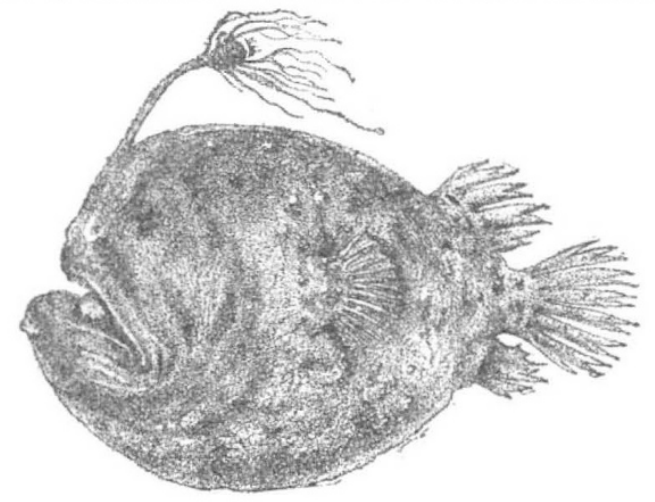

FIG. 13.-Himantolophus Rheinhardtii (Ltk.). About one-sixth of the Guinea, a closely allied animal, the nature of which he failed to understand. He must have fallen in with the animals just when they were at the surface. No doubt they are abundant at some depth or other all over the Pacific.

It seems probable that some animals which live near I From "Notes by a Naturalist," p. 573. 
the sea surface when young in all the pleasures of warmth and sunlight, sink when fully grown to lead a sluggish life on the cold and dismal bottom. Here (Fig. 13) is a remarkable deep-sea fisb. It is nearly allied to the Angler of our aquariams. It was found dead off the Greenland coast, but closely similar fish were obtained by the Challenger in great depths down to 2,400 fathoms all over the world. Mr. Agassiz also got plenty of them. The fish has a very near ally which lives on the surface amongst the gulfweed, from which it builds curious ball-like nests. You see the fish has no ventral fins, and must be, like its surface relative, a very feeble swimmer. It has very small eyes and a huge mouth, and on the top of its head is a lure set on a movable stalk, with which, like the Angler, it attracts its prey within reach of its mouth. The fish is black all over, as are most deep-sea fish, except on the lure. This is composed of numerous tentacle-like branches, which are covered with white spots, probably phosphorescent, when the animal is living. At the bases of the branches are two horn-like appendages which are white, probably also phosphorescent. The fish most likely thus manufactures its own light, whilst its tentacles, spangled with bright spots, swayed to and fro, no doubt lure many a victim to destruction. This fish is sixteen inches in actual length.

Here (Fig. I4) is what Prof. Lütken, from whom these figures are taken, ${ }^{x}$ believes to be the young of this curious

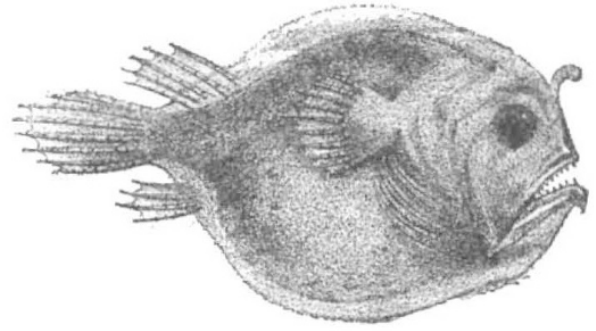

FIG. 14.-Young Himantolophus (Rheinhardtii?) from the stomach of an Albacore.

fish. It was found in the stomach of an Albacore Thynnus, a surface-living predatory fish which was caught in the tropical Atlantic. You see the little fish has, like the adult, no ventral fins. The eye is very much bigger in proportion than in the adult, but that is merely an instance of retention in the young of what has been nearly lost in the adult by disuse. Certain deep-sea blind crustacea similarly have young with fully-developed eyes. The lure on the head is just growing.

If the animal is not the young of the species just shown, which probably extends from Greenland to the tropics in the deep sea, it is certainly that of some closely-allied form. The young of other deep-sea fish have been found in the stomachs of Albacores. The young of most shallowwater bottom-living fish, such as the Angler and the flounder, pass their early existence at the sea-surface. If this deep-sea fish really develops in the early stage at the surface, how do the eggs reach the top of the water? Possibly they rise slowly from the bottom. Perhaps some other deep-sea animals go through their early stages at the surface.

According to Prof. Geikie the deep ocean basins date from the remotest geological antiquity, and Dr. Carpenter in his late lecture here maintained the same conclusion. Whether such be the case or not, any changes which may have taken place converting deep seas into shallow must have occurred very slowly, so that ample time for migration of deep-sea forms to fresh deep seas must have been afforded. Why is it therefore that very many ancient forms do not occur in the deep sea? If the ancient deep sea had been colonised say in the Silurian or Devonian ז "Vidensk. Selsk.-Skr." ${ }_{5}$ te Række, Irte Bd. v. p. ${ }_{319}$. ${ }^{2}$ Loc. cit. p. ${ }^{28}$. epochi, we should expect to find in its vast area many remnants of the fauna of that age and of subsequent geological epochs; and such was the conclusion of the late Prof. Agassiz, and of many other naturalists. It was expected that all kinds of ancient forms would be brought up by the deep-sea net. Contrary to anticipation, the deep-sea fauna is mainly composed of more or less modern shallow-water genera and their allies. The fish of the deep sea comprise amongst them no Dipnoi, no Ganoids, and no lampreys; they are allies of the cod, the salmon, and the Angler. There are no Trilobites in the deep sea, and no Graptolites, no Bellemnites. All the most ancient forms which now survive occur in shallow water. Lingula, most ancient of all, is abundant in two or three feet of water, and has, I believe, never been found below ten fathoms. Trigonia and Limulus survive in shallow water, and so do Amphioxus and Cestracion. Heliopora, the only living representative of a vast number of palæozoic corals, is a shore form.

It is true that corals which come within MilneEdwards's definition of the Rugosa occur in deep water, but that group needs great modification, and the structural difference between the deep-sea forms and ordinary Caryophyllias is probably of comparatively little zoological importance.

Though stalked Crinoids occur in deep water, they are

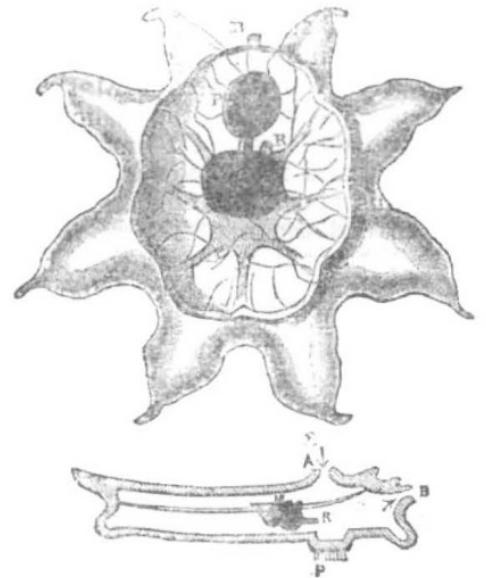

FIG. 15. I-Deep-sea Ascidian (Octacnemus Bythius). Above.-The animal viewed from below; of one half the natural size. The nucleus is seen in the centre through the transparent base of the animal. p, pedicle of attachment; B, exhalant orifice; $R$, rectum. Below.-Diagrammatic orifice; $M$, muscle attached to nucleus; other letters as in figure above.

also found in a depth of only forty fathoms. There are a certain number of forms in the deep sea which do not occur now in shallow water, and do occur as fossils in the chalk or elsewhere, but they do not form a very high percentage of the total number.

We might have expected to find surviving in the deepsea missing parts of the branches of the zoological family tree, animals of ancient pedigree which might for example have explained the affinities of the Bryozoa or the Brachiopoda, but scarcely a single animal thus of firstrate zoological importance was obtained in great depths. This is a most extraordinary fact, for in our deep-sea dredgings we have explored for the first time nearly threequarters of the earth's surface.

The most important new animal, zoologically speaking, obtained from deep water by the Challenger Expedition is, as far as I know, this Ascidian (Fig. 15), which I have named Octacnemus. Most of its body is transparent. It has eight radiate arms. Its viscera are gathered together into a small nuclear mass as in Salpa, but the nerve ganglion lies on the mass. The animal is attached to

I From H. N. Moseley, "Notes by a Naturalist on the Challenger p. 588. (Macmillan and Co., 1879.) 
the bottom by a small pedicle here. It is extremely aberrant in structure. It is from 1,070 fathoms.

Most of the interesting forms obtained by us are from comparatively shallow water. As an example may be cited Syllis ramosa of Dr. McIntosh, which is from 90 fathoms. It is a worm which branches in a most extraordinary manner, quite unlike any other annelid known. The entire body divides up into a series of complex ramifications. Nevertheless, as shown by Dr. McIntosh, ${ }^{\mathrm{I}}$ the worm belongs to a well-known shallow-water genus, Syllis. The head or heads of the animal were all broken off the single specimen obtained, and it is uncertain how many it may have had. The animal lives embedded in a sponge, in the canals of which its ramifications are received.

(To be continued.)

\section{NICHOLAS ZININ}

$W^{E}$ have already briefly alluded to the death of the veteran Russian chemist Prof. Zinin, which occurred at St. Petersburg, February 19. Nicholas Zinin was born August 13, 1812, at Choucha, in the Caucasus district. After completing the course of studies in the Government Gymnasium at Ssaratow, on the Volga, he entered the University of Kasan, where he is recorded as the recipient of two gold medals for superiority in mathematical and physical ștudies. In 1833 he finished the ordinary course of studies in the mathematical faculty. In 1836 he received the degree of Master of Sciences from the university, and in the following year was appointed assistant professor. At first his lectures were confined to physics and mechanics; later they embraced chemistry. At this epoch the educational authorities of Russia began to feel the necessity of a more intimate familiarity with the rapid progress then being made in chemistry in Occidental Europe, and it was decided to send the young professor to gain a personal knowledge of the methods then in vogue in the laboratories of the West for furthering chemical research. His face turned naturally towards Giessen, where Liebig had already gathered about him a brilliant circle of young and enthusiastic chemists of the most diverse nationalities. A special favourite of the great master, his abilities as an independent investigator were rapidly developed. After passing some years at Giessen, and in journeying through England, France, and Switzerland for the purpose of scientific observation, Zinin returned to Russia to receive the degree of Doctor of Sciences from the University of St. Petersburg. Until 1848 he continued in his professorship. At that date, however, attention had been so strongly drawn to his talents as a lecturer and as an investigator, that he was elected to the chair of chemistry in the Imperial Academy of Medicine at St. Petersburg. This position he continued to occupy until 1874 , when he retired from active professiorial duties.

Zinin's first researches, made under Liebig's direction, were devoted to the products of decomposition of the oil of bitter almonds, to a new method of preparing benzilic acid, and to the formation of various compounds in the benzoylic series. They indicated painstaking labour and an unusually thorough insight into the nature of the reactions taking place In 1842 he published a short research which attracted universal attention in the chemical world. It was entitled "Organic Bases Resulting from the Action of Sulphuretted Hydrogen on Nitro-naphthalene and Nitro-benzene," and described for the first time the formation of bases from nitro-compounds by means of reducing agents. It is chiefly in connection with this discovery that Zinin's name will remain closely associated. The interest excited at the time of its announcement was purely of a scientific character, but after a lapse of fifteen years it assumed a ${ }^{t}$ Linn. Soc. Fourn. Zoology, vol, xiv. p. 720, 1879 . commercial importance of the highest kind, and to-day manufacturing interests involving many millions are based on that simple reaction of reducing nitro-compounds, to which we owe all the wealth of colour derived from aniline and its homologues. In 1844 he followed up the same line of discovery by producing the bases derived from the dinitro derivatives of benzene and naphthalene. By means of the same reaction he obtained also in 1854 the amido acid from nitro. anisic acid. In this connection should be mentioned likewise the interesting production of oxanaphthalide and formonaphthalide from oxalate of naphthylamine under the influence of heat $\left(185^{8}\right)$. In 1852 he discovered the formation of diamidodiphenyl by the action of sulphurous acid on azobenzene, a reaction which he found some twelve years afterwards to be induced also by hydrochloric acid. The nitro-derivatives of azobenzene and azoxybenzene were also submitted to a thorough investigation by him (1860). In 1852 he discovered likewise the aromatic thiosinnamines due to the action of mustard oil on aniline, naphthylamine, \&c. I 854 witnessed the discovery of the ureides, the important class of compound ureas obtained by exposing urea to the action of acid chlorides or anhydrides. In this manner he prepared the first types of this group : acetureid $\mathrm{CO}_{\mathrm{NH}}^{\mathrm{NH}_{2}} \mathrm{C}_{2} \mathrm{H}_{3} \mathrm{O}$, benzureide, butylureid, and valerureide. In the following year $Z$ inin increased the then comparatively limited number of organic compounds occurring in nature, or resulting immediately from the simple decomposition of natural bodies, which could be prepared artificially, by the synthesis of oil of mustard from allyliodide and potassium sulphocyanide. At the same time he claimed for the allyl group its now accepted position among the alcohol radicals, and prepared a number of allylic ethers in order to prove its ability to replace hydrogen atoms in acids. In 1857 he returned to the field of investigation which had enlisted his interest while under Liebig's guidance, viz., the study of benzoin and its derivatives; and with few exceptions his researches up to the close of his life were confined to this subject. At this date he succeeded in introducing acid radicals into benzoin by exposing it to the action of acid chlorides, and prepared in this way acetyl- and benzoyl-benzoin. In I 860 he was successful in regenerating benzoin from benzilethe product of its oxidation-by making use of reducing agents. At the same time he prepared a number of derivatives of benzile. Hydrobenzoin was also obtained by him in 1862, as the result of reducing the oil of bitter almonds. In this connection may be mentioned his elaborate study, in 1868, of Laurent's benzimide-the complicated amide resulting from the action of acids on the oil of bitter almonds - in which he showed it to be a combination of the latter with the imide of formobenzylic acid. In $1867 \mathrm{Zinin}$ submitted benzoin to the action of hydrochloric acid, and obtained a compound, $\mathrm{C}_{28} \mathrm{H}_{20} \mathrm{O}$, named by him lepidene. This body was studied exhaustively by him throughout a series of years. While unable to fathom the mysteries of its constitution, he prepared an extensive array of derivatives, oxylepidene, dioxylepidene, oxylepidenic acid, many products of substitution, \&c., of nearly all of which two or more isomerides were obtained. So thorough was the study of the relations existing between the members of this series, that they will all fall into naturally-assigned places when once the bond between the lepidene group and bodies of known constitution is fairly established. In $186 \mathrm{I}$, by the reduction of benzoin, he obtained desoxybenzoïn, $\mathrm{C}_{14} \mathrm{H}_{12} \mathrm{O}_{2}$, a compound which the reduction of chlorobenzile likewise yielded him a few years later. This body he changed by the action of nitric acid into nitrobenzile; and in 1868 . by successive treatment with phosphorus pentachloride and reducing agents or potash, he changed it into stilbene and tolane, thus throwing an interesting light upon the constitution of benzoin and its deriyatives. In 1870 he 